\title{
ENVIRONMENTAL MICROCLIMATE MANAGEMENT AND RISK IN THE UNESCO WORLD HERITAGE SITE OF VILLA BARBARO MASER (ITALY)
}

\author{
A. Bonora ${ }^{1}$, K. Fabbri ${ }^{1}$, M. Pretelli ${ }^{1}$ \\ ${ }^{1}$ University of Bologna, Department of Architecture, Bologna, Italy - (anna.bonora3, kristian.fabbri, marco.pretelli)@unibo.it
}

KEY WORDS: Historic Indoor Microclimate (HIM), Heritage Microclimate Risk (HMR), Microclimate, Heritage Building (HB), Building Simulation (BS), Validation

\begin{abstract}
:
Indoor environment in heritage buildings can be cause of damage for architecture and artefacts which depend on several physical and chemical parameters: air temperature, relative humidity, volatile organic compounds, etc. How is it possible to evaluate their damage, or the risk of damages? How "aggressive" is indoor microclimate? The scientific literature proposes several different criteria for the evaluation of the risk of damages, especially in the field of museums, while there are few studies which take into consideration historic buildings. In this paper we propose an index -the Heritage indoor Microclimate Risk (HMR)- that allows to define the risk concerning the whole environment and not only the artefacts. Moreover, we propose its application to a real case study of a UNESCO Heritage World Site, obtained through indoor microclimate on-site monitoring and building simulation. The case study reported is Villa Barbaro, built in Maser (1554-1560) by the architect Andrea Palladio and registered in the UNESCO World Heritage Site list since 1996, as Palladian Villa of Veneto. The research is structured as follows: monitoring campaign of the microclimatic parameters; virtual modelling of Villa Barbaro and its validation (by comparing the simulated data and the monitored ones); construction of scenarios which can aid to guarantee the historic building's conservation and the occupants' comfort; definition of HMR. The innovative aspect of the proposed methodology is the use of a virtual building model of heritage buildings, to determine, through a single index, the degree of risk and the level of indoor microclimate aggression.
\end{abstract}

\section{INTRODUCTION}

The cultural heritage sector represents a field of research in which we can find two different approaches: on one hand the humanistic side, aimed at discovering the history of artefacts; on the other hand, the scientific attitude, concerned with finding the evaluation modalities for the preventive conservation. In addition, there are scientific guidelines and other disciplines such as restoration, law, physics, biology, chemistry, etc., which study specifically the sector: we can put them all under the term "Heritage Science".

Heritage Science studies the building and the single artefacts kept inside it, both when the building studied is a historic one and also when we are talking about a modern building, especially if this is a museum. In the latter example the aim of the design of the building must be to preserve good indoor microclimatic conditions: attention must be always paid to guarantee that the conservation's ranges are respected, to assure an optimal preservation (and the availability) of the goods exposed.

The subject of this study is the "Indoor Microclimate". Literature already exists over this subject, in the area of museums scientists as Thomson (Thomson, 1986) and Camuffo (Camuffo, 1998), define the physical variables, the degradation levels and, partially, the monitoring methodology (indoor and outdoor); also, in Italy, this is an issue which has been particularly emphasized, for example by Bernardi (Bernardi, 2008); moreover, exist Standards (UNI 10829 EN 15759), which identify specific ranges of the parameters, allowing the preservation of artworks in relation to their nature. The American society ASHRAE ${ }^{1}$ defined and updated many times the design guidelines for the microclimate control of museums,

1 American Society of Heating, Refrigerating and AirConditioning Engineers. libraries and archives; moreover, institutions as $\mathrm{ICOM}^{2}$ and $\mathrm{ICCROM}^{3}$, have historically operated in this field, in terms of sensibilisation and research. Several studies carried out by researchers, whose are part of those institutions, underline the importance of the environmental control, aimed to reduce the material damage and facilitate the preventive conservation. De Guichen is a great example of this: he proposed specific methodologies for museums.

Nevertheless, in our opinion, today there isn't a vision which includes the history and the objectives of the project regarding heritage science. In this regard, Historic Indoor Microclimate (HIM) has been defined (Fabbri and Pretelli, 2018). There is a crucial connection between indoor microclimate and architectural configuration, deduced through the study of HIM. The HIM approach refers to the historic buildings' indoor microclimatic conditions, in contrast to the traditional approach, that focuses on the conservation's range of singular assets. Once a sound knowledge of the indoor microclimate is acquired, it is possible to verify and to simulate the state of conservation of the objects and the occupants' comfort. We believe this is the most interesting aspect of the proposed methodology presented below: the virtual building simulation allows to formulate hypothetical present, past or future scenarios of management (access, collections, maintenance management tasks, etc.). The novelty of the paper is the synergy or combination of the two aspects of the approach to get an index of risk. The specific index proposed - "Heritage Microclimate Risk" (HRM) - aims to assess the indoor microclimate "aggressiveness" towards buildings and artefacts.

Understanding the indoor microclimate conditions permits to make considered choices in order to achieve the preventive

\footnotetext{
${ }^{2}$ International Council Of Museums.

${ }^{3}$ International Centre for the Study of the Preservation and Restoration of Cultural Property.
} 
conservation of heritage buildings and their hosted artefacts, considering the question of accessibility and visitors' comfort.

\section{MAIN BODY}

\subsection{What does Historic Indoor Microclimate mean?}

In the last decade several articles have been published on heritage buildings' indoor and outdoor microclimate, but - in our opinion - these researches have not a common framework, and this is one of the reasons why none of these are replicable for other case studies. Indeed, scientific literature reports a series of case studies with different kinds of research methodologies, reference standards, monitoring tools, measurement strategies and also different software are used. The scientific literature on indoor microclimate is composed by specific experiences: historic library, Malatestiana Library (Fabbri and Pretelli, 2014a), focused on temperature and relative humidity and Classense Library monitoring, (Andretta, 2016a) focused on chemical pollutants; expositions in museums (Corgnati and Filippi, 2010a), museums in historic buildings (Gennusa et al. 2005a) valuable case studies as the monitoring of the Scrovegni Chapel (Bonacina et al, 2015a) and the La Specola museum in Florence (Sciurpi et al. 2015a). Other researches concern microclimate in museums and strategies for the diagnosis or for certification, such as the evaluation protocols of microclimate in museums (D'Agostino, D'Ambrosio Alfano, Palella, Riccio, 2015a), (Kramer et al. 2016a), (Pavlogeorgatos, 2003a), (Ankersmit, 2017) and ASHRAE Guideline for Museums, Galleries, Archives (ANSI/ASHRAE, 2015b).

The MIBACT (Ministry of Cultural Heritage and Activities and Tourism) has its own regulation (MIBACT, 2001) in which the ranges for conservation of the artefacts are identified, but just for confined smaller environments, such as display cases: there are no standards or benchmarks for architectural environments.

We can define the HIM as the study of the evolution of the characteristic microclimate of an architectural structure over time, in relation to its use, the changes that involve it in structural terms and finally the introduction of HVAC systems. Also the standards, as well as the ASHRAE Guideline, concern the indoor microclimate of Cultural Heritage, referring to specific materials as the ISO 11799 for library materials, EN 15757 for organic hygroscopic materials, that defines the microclimate as "climate on a small spatial scale", the indoor environment as an "area within a building where cultural heritage objects are preserved" and the historical climate as "Climatic conditions in a microenvironment where a cultural heritage object has always been kept, or has been kept for a long period of time (at least one year) and to which it has become acclimatized", talking thus of a one-year period. In this last definition we find the conceptual gap, which is the subject we would like to focus on with this research and the future ones.

The definition of the Standard UNI EN 15757 regards the characteristic indoor microclimate to which a specific object has been accustomed for a lot of time, but it doesn't define any specific environmental parameters.

Our approach puts the Cultural Heritage's microclimate at the heart of the matter, under two aspects:

- The HIM is used to find out the building's history, considering how and what has changed inside and outside the building over time (destination of use, plant, climate changes, etc.);

- The indoor microclimate is the context where there are the artefacts which we want to preserve, as walls, frescoes, structures, fixtures, paintings, furniture, etc.
For what concerns the second aspect, we want to verify the level of the indoor microclimate aggression: the degree of risk which threatens the artefacts.

In the field of heritage indoor microclimate, we don't have a common nomenclature that allows to communicate with other non-scientific experts (e.g. historians, museum curator, artists, restorers, administration, standards, etc.). Regarding the connection between the Risk and the Microclimate, there are some researches with different approaches: Risk Based (Silva, et al., 2016a), Multidisciplinary Risk described in all-inclusive review of Lucchi (Lucchi, 2016a), (Lucchi, 2017b), Climate Risk (Brokerhof et al. 2017) and Global Climate Change and Cultural Heritage (Chiari et al. 2007).

\subsection{Research Methodology}

The adopted research methodology provides three levels of analysis:

1) Understand the building, through:

- archive research: verifying the historic building's geometrical, structural and thermo-physical characteristics; moreover, information over the use of the venue has been obtained thanks to the then current owner;

- on-site monitoring: recording the Actual Indoor Microclimate (AIM) characteristics;

2) Virtual Building modelling and simulation:

- Building simulation: the realisation of a Virtual Building model and the pertaining Virtual Environmental model to reproduce the same characteristics of the case study;

- Model validation: comparing the simulated data to the ones obtained by probes during the indoor microclimate campaign.

- Virtual Scenarios: once the virtual building model gets validated, it is possible to modify many parameters, to see how could change the building's and artefacts' condition in a different scenario (which could be caused by a Climate Change; activation/deactivation of the HVAC; opening/closing windows management, ecc.);

3) Proposal of a Heritage Microclimate Risk (HMR), applied to the specific case study of Villa Barbaro Maser.

The strength of the proposed methodology lies in the possibility of defining in advance which actions can help the preservation of the artefacts, through a virtual building model that represents reality, avoiding thus the risk factors of directly modifying the real building.

\subsection{Archive search}

The chosen case study, Villa Barbaro Maser, built by Andrea Palladio, has been part of the UNESCO World Heritage Site list since 1996 and there is a lot of research material related to it. This and the help of the current owner, allowed us to find a lot of useful historical and architectonical information. Moreover, we used the graphic papers elaborated between 1968 and 1981 by the International Centre of Architectural Studies Andrea Palladio (CISA, Istituto di ricerca sulla storia dell'architettura antica e moderna, founded in 1958) and the essay "The Four Books of Architecture" by Andrea Palladio [35], to find the passages in which he provides indications and suggestions.

\subsection{Monitoring campaign}

Microclimate monitoring allows to detect the microclimatic conditions of indoor and outdoor environments. The possibility to check all the environmental factors that determine the microclimate allows us to identify the conservation criteria for 
the objects situated inside the analysed area and to find the structural or temporary causes of deterioration and also allows us to maintain, in time, the best possible conditions, respecting the norms and the parameters of the law.

Literature can be found over several "museum monitoring experiences", such as Correr Museum, Venezia (Camuffo, Brimblecombe, Van Grieken, Busse, Sturaro, Valentino, Bernardi, Blades, Shooter, De Bock, Gysels, Wieser, Kim, 1999a) or University of Palermo (Costanzo, Cusumano, Giaconia, Giaconia, 2006a).

On-site monitoring requires to choose the position to place the probes, their setting, the definition of the duration of the monitoring campaign and the selection of the microclimatic parameters which are, at least: Air Temperature (measured in ${ }^{\circ} \mathrm{C}$ ), Relative Humidity (measured in \%), Illuminance (measured in lux) and Carbon Dioxide ( $\mathrm{CO}_{2}$ measured in $\left.\mathrm{ppm}\right)$.

To choose the instrumentation and the monitoring modality we used the Standards UNI EN 15758 , UNI 10829, UNI 11131, UNI 11120, EN 15759-1 as a reference.

The monitoring campaign in Villa Barbaro lasted for six months: from 21/06/2016 to 9/12/2016.

The Wireless Sensor Network Beesper (Beesper-WSN) monitoring system, produced by Henesis, enables online data transmission in real time and the use of a remotely visualisation of data.

The monitoring system is composed by:

- Beesper Nodes, with sensors to monitor microclimatic parameters: illuminance (measured in lux), Air Temperature $\left({ }^{\circ} \mathrm{C}\right)$, Relative Humidity $(\%)$ and Carbon Dioxide $\left(\mathrm{CO}_{2}\right.$ measure in $\mathrm{ppm}$ ). The $\mathrm{CO}_{2}$ indicates the quality of the air and the presence of visitors;

- Beesper Bridge, that records data sent by the nodes through the Wireless system. The Bridge transmits these data to the main online platform: the Beesper Console;

- Beesper Console, an online platform to remotely visualise the data.

We monitored three of the six rooms open to the public. We placed the bridge in the room "Croce Centrale" (Figure 2), and the probes in room "Croce Centrale", room "Stanza del Cane" and room "Tribunale d'Amore". In the layout (Figure 1), these rooms correspond respectively to number 1,2 and 3 .

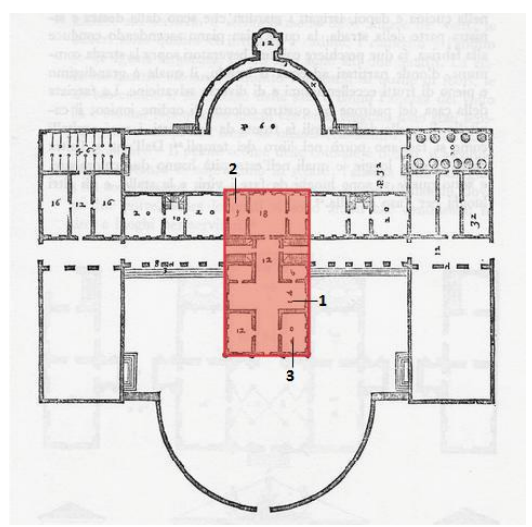

Figure 1. Villa Barbaro. In red, the rooms open to the public.

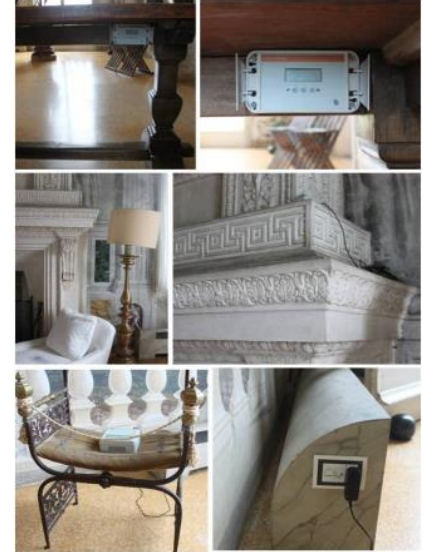

Figure 2. Beesper Bridge in the room "Croce Centrale" (top photos); Beesper Node in the room "Stanza del Tribunale d'Amore" (central photos); Beesper Node in the room "Croce Centrale" (bottom photos).

\subsection{Simplification adopted}

During the research we found some anomalies. Due to a failure of a probe we couldn't retrieve data from the room (2) "Stanza del Cane". There is a gap in the data collected, between $6^{\text {th }}$ October and $10^{\text {th }}$ December, caused by a dead battery in the Bridge. Nevertheless, these anomalies can be considered irrelevant for this case study: we can propose and calculate an HMR of Villa Barbaro anyway.

To realise the 3D virtual model of Villa Barbaro, we adopted some geometrical simplifications for the windows, because of certain thermal imbalances errors, which have been solved converting the arched elements into square ones.

\subsection{Building simulation}

The structure of Villa Barbaro is a typical three-layered rubble masonry: the two external faces include an internal, less regular, brickwork layer. The external walls are approximately $0.80 \mathrm{~m}$ thick and the internal ones $0.65 \mathrm{~m}$ on average. The stone is used only for the decorations: capitals and frames. The doors and the windows' fixtures are wooden; the windows are singleglazed, and the roof is made of concrete and bricks.

The building has a HVAC system, a heating system with fancoils, introduced during the $50 \mathrm{~s}$ of the XX century. Actually, the HVAC system is always off, so it can't be taken into consideration.

Presently, Villa Barbaro is partly residential building and partly museum: only six rooms are accessible to the public and three of those have been monitored during the monitoring campaign illustrated below. In these rooms the HVAC system is never active, even though it works: the last systems adaptations date back to 2000, approximately. Moreover, to protect the original flooring, the visitors must use specific shoes provided to them at the entrance.

The Building Simulation consists on the use of a Virtual Model, realised with a computerized simulation, which allows to examine several specific aspects of a building. For the Indoor Microclimate, Building Performance Simulation (BPS) is used, a generic term for virtual building models. It allows to study the performance of the building: indoor microclimate, lighting, energy, human behaviour, acoustics, indoor air quality, etc. Also, we used a software to assess the Computational Fluid Dynamics (CFD): a simulation of the fluid dynamic behaviour of the air, indoor and outdoor, resulting from natural ventilation. 
We realised the Building Simulation through the IES.VE software (Virtual Environment by Integrated Environmental Solutions: software BIM - Building Information Modelling). Thanks to the layout of the building on AutoCAD, we realized the 3D model of Villa Barbaro (Figure 3) using the SketchUp software. After that, downloading a plug-in, we transferred this model on IES.VE: a dynamic simulation software. IES.VE has a module for CFD modelling; it gives back information on energy use, $\mathrm{CO}_{2}$ emissions, people comfort, light levels, airflow, etc., through data, images and videos.

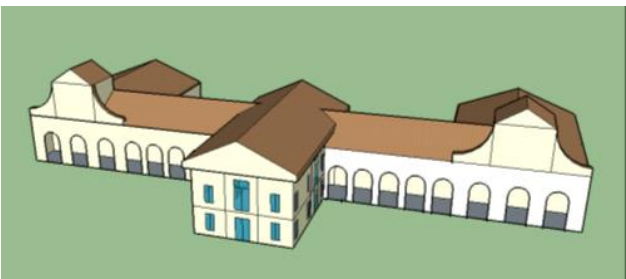

Figure 3. 3D Model of Villa Barbaro in Google SketchUp

\subsection{Validation of the virtual building model}

The virtual building model allows to elaborate selected microclimate improvement scenarios. For this case study, the scenarios tabled cannot propose modifications to the architecture of the building: the only interventions permitted are those of the management of people inflow and of the heating systems already in existence.

We measured the hypothetical indoor thermal comfort of visitors, turning on the HVAC system. The scenarios simulated on IES.VE suggests a management of the indoor Air Temperature $(\mathrm{T})$, which is the specific parameter that turns out to be the most dangerous in terms of HMR, based on the standards and the monitoring campaign.

Setting on IES.VE a set-point of $18^{\circ} \mathrm{C}$ for the heating and $24^{\circ} \mathrm{C}$ for the air conditioning, we simulated the indoor microclimate and the visitors' comfort that would result out of these conditions, more specifically the PMV (Predicted Mean Vote) and the PPD (Predicted Percentage of Dissatisfied) according to ISO 7730. The objective of this study is to identify an index that helps evaluate the effectiveness of these scenarios, precisely the comparison between the present HMR and that of the simulated scenarios. The HMR results of the simulated $\mathrm{T}$ are shown in paragraph 3 (Conclusions).

The virtual building model has been validated through the monitoring campaign data, as reported in Table 1.

\begin{tabular}{|c|c|c|c|}
\hline $\begin{array}{l}\text { Validation } \\
\text { parameter }\end{array}$ & $\begin{array}{c}\text { Room } \\
\text { Tribunale } \\
\text { D'Amore } \\
\end{array}$ & $\begin{array}{c}\text { Room } \\
\text { Croce } \\
\text { Centrale } \\
\end{array}$ & \\
\hline MBE & $2.01 \%$ & $1.92 \%$ & $\begin{array}{c}\text { MBE (Mean Bias } \\
\text { Error) Validate if } \\
\text { MBE }<10 \%\end{array}$ \\
\hline CV (RSME) & $13.00 \%$ & $13.37 \%$ & $\begin{array}{c}\text { coefficient of } \\
\text { variation root- } \\
\text { mean-square error } \\
\text { (RMSE) Validated } \\
\text { if CV (RMSE) < } \\
30 \% \\
\end{array}$ \\
\hline PEARSON & 0.95 & 0.94 & $\begin{array}{l}\text { Pearson Correlation } \\
\text { Coefficient } \\
\text { if }>0.7=\text { strong } \\
\text { correlation, } \\
\text { if between } 0.3-0.7 \\
=\text { correlation }\end{array}$ \\
\hline
\end{tabular}

\begin{tabular}{|c|c|c|c|}
\hline $\begin{array}{l}\text { Coefficient of } \\
\text { determination } \\
\mathrm{R}^{2}\end{array}$ & 0.89 & 0.87 & $\begin{array}{c}\text { Validated if } \mathrm{R}^{2}> \\
0.5\end{array}$ \\
\hline \multicolumn{4}{|c|}{$\begin{array}{l}\text { Reference for validation parameters: (ASHRAE, 2002b); } \\
\text { (ASHRAE, 2011b); (Royapoor and Roskilly, 2015); (Roberti et } \\
\text { al., 2015a). }\end{array}$} \\
\hline
\end{tabular}

\subsection{Heritage Microclimate Risk}

What's lacking in the Heritage Science and Indoor Microclimate sector? The Microclimate Risk proposal.

The measurements obtained from the monitoring and the virtual building simulations, allow to assess the percentage of the Heritage Microclimate Risk (HMR) to which the artefacts are subject.

The Heritage Microclimate Risk (HMR) definition is useful for the activation of any intervention which could facilitate the management of the microclimate, not only in case of touristic use, but also for museums or residential buildings, that is to say for everyone who lives in them and for the conservation of buildings themselves.

HMR allows a prior estimate of the interaction between the artefact and the indoor microclimate, and it is measured considering the indoor microclimatic typical standards: Air Temperature, Relative Humidity, Illuminance and Carbon Dioxide $\left(\mathrm{CO}_{2}\right)$. It is calculated as follows:

$H M R=\frac{m n_{h}}{h}$

and regarding the single variable $(\mathrm{x})$

$\operatorname{HMR}_{(x)}=\frac{m n_{\mathrm{h}}(x)}{h}$

Where

$\mathrm{mr}_{\mathrm{h}}=$ hourly microclimate risk of the reference period;

$\mathrm{h}=$ total hours of the reference period.

The reference period can be defined on the basis of the monitoring campaign duration (week, month, year) and the representativeness of data (number of the survey).

The period of monitoring established by the Standard UNI 10829 is 1 year; nevertheless, in the scientific literature we can find researches of only one week, or one month or one or two years of monitoring, and also concerning specific weeks in different seasons. This period depends on the operative procedures and possibilities. The reference period is not the object of this research and the authors don't want to open a debate about it, especially without relevant legislation and consolidated research methodologies in the scientific literature. In this case study the reference period corresponds to the monitoring campaign.

The $\mathrm{mr}_{\mathrm{h}}$ (hourly microclimate risk) is determined by

$m r_{h}=\sum_{j=1}^{n}\left(h r_{(x)}>h r_{(x, s e t), \min }\right)_{j}+\left(h r_{(x)}<h r_{(x, s e t), \max }\right)_{j} \quad$ [h]

Where

$\mathrm{hr}_{(\mathrm{x})}=$ heritage risk of the microclimatic variable (x);

$\mathrm{hr}_{(\mathrm{x}, \mathrm{set}) \text { min }}=$ heritage risk of the microclimatic variable $(\mathrm{x})$ with the minimum set-point, defined as the lower range established by Standard (UNI 10829, 1999) or other guidelines;

$\mathrm{hr}_{(\mathrm{x}, \mathrm{set}) \text { max }}=$ heritage risk of the microclimatic variable $(\mathrm{x})$ with the maximum set-point defined as the lower range established by Standard (UNI 10829, 1999) or other guidelines; $\mathrm{j}=$ number of hours of the reference period.

Therefore, $\mathrm{mr}_{\mathrm{h}}$ expresses the number of hours of the reference period, during which the value of the specific microclimatic variable (x) doesn't comply with the conservation range. The calculation is done for each specific microclimatic variable. 
The level of the $H M R$ is here defined with a hazard classification (HMR Class) from "Low Risk" to "Extreme Risk", as shown in Table 2.

\begin{tabular}{|c|c|l|}
\hline $\begin{array}{c}\text { HMR range } \\
\text { value }\end{array}$ & $\begin{array}{c}\text { Hazard } \\
\text { classification } \\
\text { (HMR Class) }\end{array}$ & $\begin{array}{c}\text { Characterising indicators } \\
\text { of risk (HMR traits) } \\
\text { Qualitative Description }\end{array}$ \\
\hline$<25 \%$ & LOW & $\begin{array}{l}\text { There is no risk for the } \\
\text { artefacts in the environment. }\end{array}$ \\
\hline $25 \%-50 \%$ & MODERATE & $\begin{array}{l}\text { There are possible risks for } \\
\text { the artefacts, in specific } \\
\text { management conditions of } \\
\text { the environment. }\end{array}$ \\
\hline $50 \%-75 \%$ & MARKED & $\begin{array}{l}\text { There are possible risks for } \\
\text { the artefacts, due to the } \\
\text { current management } \\
\text { conditions of the } \\
\text { environment. }\end{array}$ \\
\hline$>75 \%$ & EXTREME & $\begin{array}{l}\text { The environment represents a } \\
\text { risk for the artefacts, most of } \\
\text { the time. }\end{array}$ \\
\hline
\end{tabular}

Table 2. Levels of qualitative HMR

\subsection{Monitoring campaign results}

For the specific case study of Villa Barbaro, we referred to the UNI 10829 and to MIBACT [28], for the ranges of $\mathrm{T}$ and Relative Humidity (RH). This building is characterised by the presence of many frescoes, for this reason, to calculate the HMR, we considered the limits suggested for the conservation of the category "inorganic materials/articles":

- $\quad$ Air Temperature $\mathrm{hr}_{(\mathrm{t}, \text { set }) \text { min }}=15^{\circ} \mathrm{C}$ and $\mathrm{hr}_{(\mathrm{t}, \mathrm{set}) \max }=25^{\circ} \mathrm{C}$;

- Relative Humidity $\mathrm{hr}_{(\mathrm{RH}, \mathrm{set}) \min }=20 \%$ and $\mathrm{hr}_{(\mathrm{RH}, \text { set }) \text { max }}=60 \%$.

It turns out that in the room "Croce Centrale" the $\mathrm{HMR}_{(\mathrm{RH})}$ is $32,31 \%$ and the risk concerning the Air Temperature $\left(\mathrm{HMR}_{(\mathrm{T})}\right)$ is $86,91 \%$ (Figure 4); in the room "Tribunale d'Amore" the HMR percentages caused by RH and T are respectively 33,78\% and $84,38 \%$ (Figure 5). The green area in the figures, represents the range of the reference standard.

The microclimatic risk caused by $\mathrm{RH}$, which has been recorded for each room, corresponds to a "Moderate" risk, with percentages of about $30 \%$, whereas the one caused by $\mathrm{T}$ exceeds 80\%: "Extreme" risk.

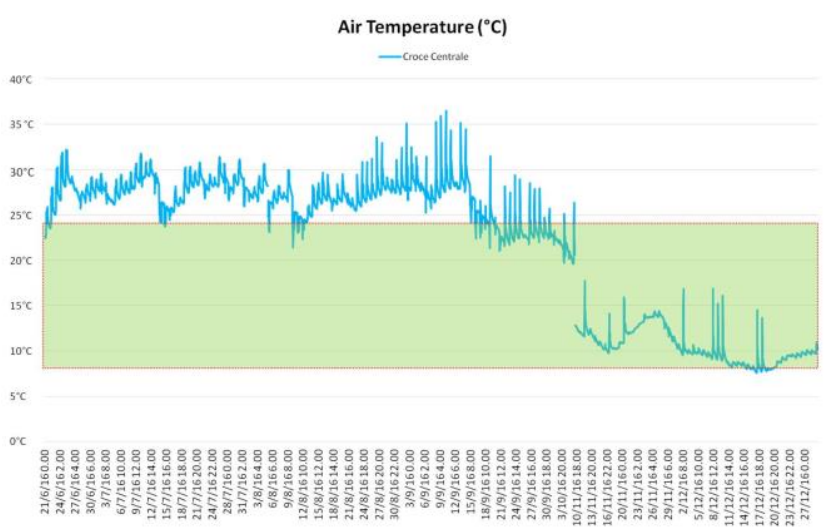

Figure 4. Air Temperature Trend and $\mathrm{HMR}_{(\mathrm{T})}$ Range, Room (1) Croce Centrale

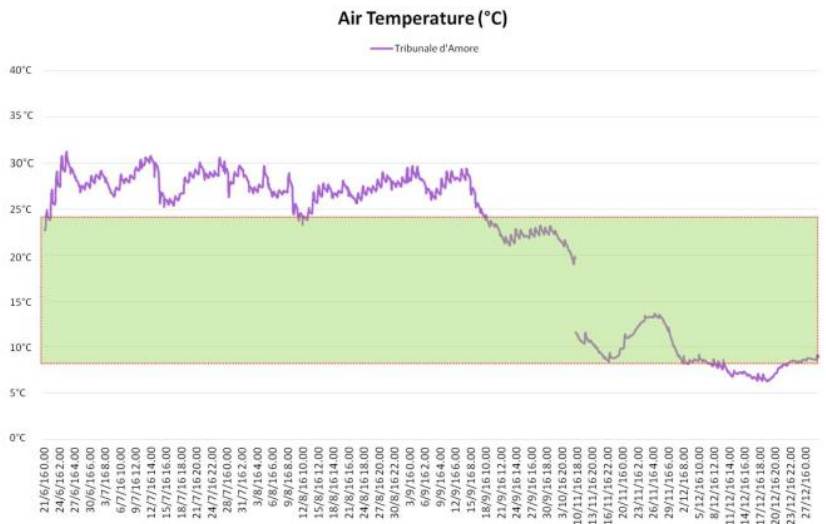

Figure 5. Air Temperature Trend and $\mathrm{HMR}_{(\mathrm{T})}$ Range, Room (3) Tribunale D'Amore

In both rooms trends of $\mathrm{T}$ show a temperature above $25^{\circ} \mathrm{C}$ during the summer months, sometimes also above $30^{\circ} \mathrm{C}$ and in winter, in certain days, it is as low as $7^{\circ} \mathrm{C}$. This situation clearly shows that the HVAC system is off, therefore the volume of air is influenced by the trends of the outdoor temperature.

$\mathrm{RH}$ trends range between $35 \%$ and $80 \%$ (during the winter months, corresponding to days of rain or fog) for each room. Figure 6 shows that the temperature leap between day and night is wider during summer rather than in winter, except for some winter days, when $\mathrm{T}$ is affected by the direct solar radiation through the big windows in the room "Croce Centrale". Moreover, the RH trend is inversely proportional to that of $\mathrm{T}$. The temperature leaps shown in Figure 7, registered in room "Tribunale d'Amore", are smaller than those recorded in the room "Croce Centrale". The values are more "stable" because the air volume is smaller and, especially, because in the room "Tribunale d'Amore" there is only one window through which the direct solar radiation can enter.

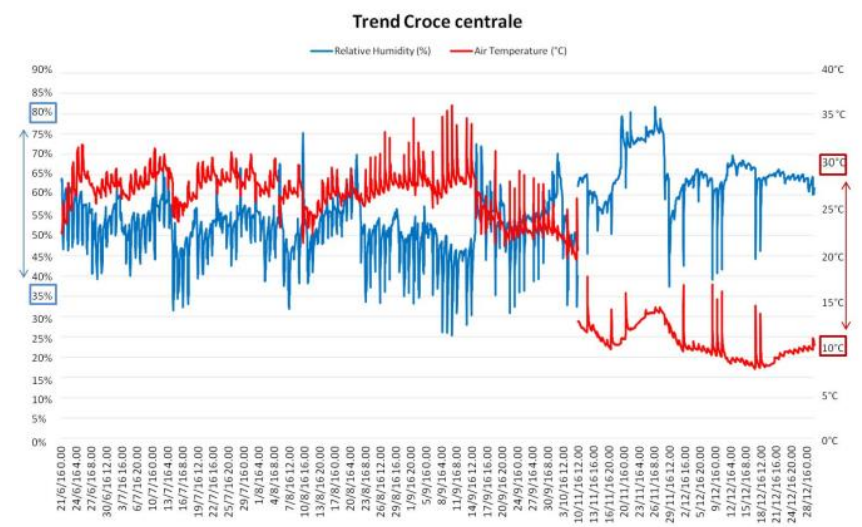

Figure 6. Air Temperature and Relative Humidity Trends, Room (1) Croce Centrale 


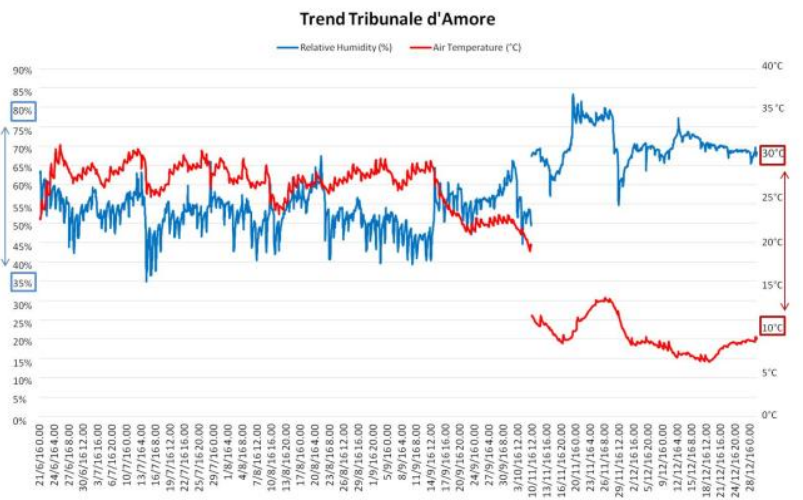

Figure 7. Air Temperature and Relative Humidity Trends, Room (3) Tribunale D'Amore

\subsection{Building simulation results}

The IES.VE building simulation allowed us to extrapolate: the spatial distribution of $\mathrm{T}$, two different scenarios on the thermal comfort of visitors, based on the percentage of PPD; the current condition (HVAC-OFF) and with a simulation of the heating ventilation and air conditioning system turned on (HVAC-ON). The set-point used for the Apache and fluid dynamic simulation are $18^{\circ} \mathrm{C}$ for the heating and $24^{\circ} \mathrm{C}$ for the air conditioning. Interesting results emerge from the comparison between the trend of T simulated in both scenarios: HVAC-ON and HVACOFF, showed in Figure 8 and 9. The reference period for simulations is the same as of the monitoring campaign. The graphs show a similar trend only during autumn, September and October 2016. This confirms the role that thermal plants could have to stabilise $\mathrm{T}$, as the trend of HVAC-ON shows.

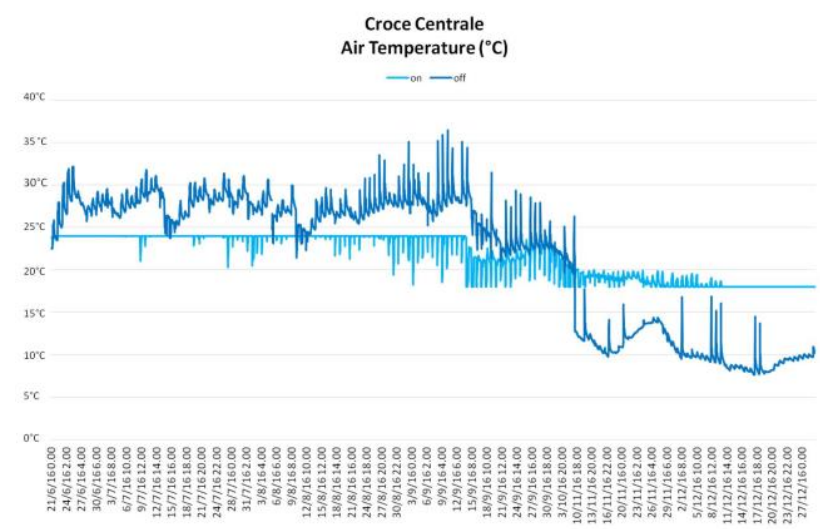

Figure 8. Air temperature trend in building simulation HVACON and HVAC-OFF Scenarios, room "Croce Centrale".

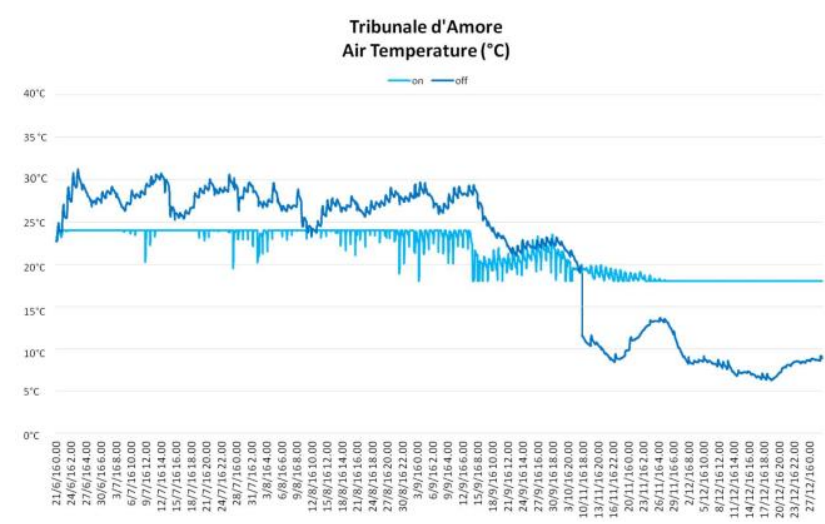

Figure 9. Air temperature trend in building simulation HVAC ON and HVAC-OFF Scenarios, room "Tribunale D'Amore".
Figure 10 shows $\mathrm{T}$ spatial distribution at a height of $1.60 \mathrm{~m}$ above the floor level, considering the HVAC-ON. All the simulations concern a specific day for both seasons: $2^{\text {nd }}$ of July 2016 in Summer and $29^{\text {th }}$ of December in Winter. To clarify: we did the simulation for a whole year, but we report just the results of these two days as an example. These two days are respectively the one with the maximum and minimum energy input (as results from the IES.VE simulations during opening hours: between $8.00 \mathrm{AM}$ and 6.00 P.M.).

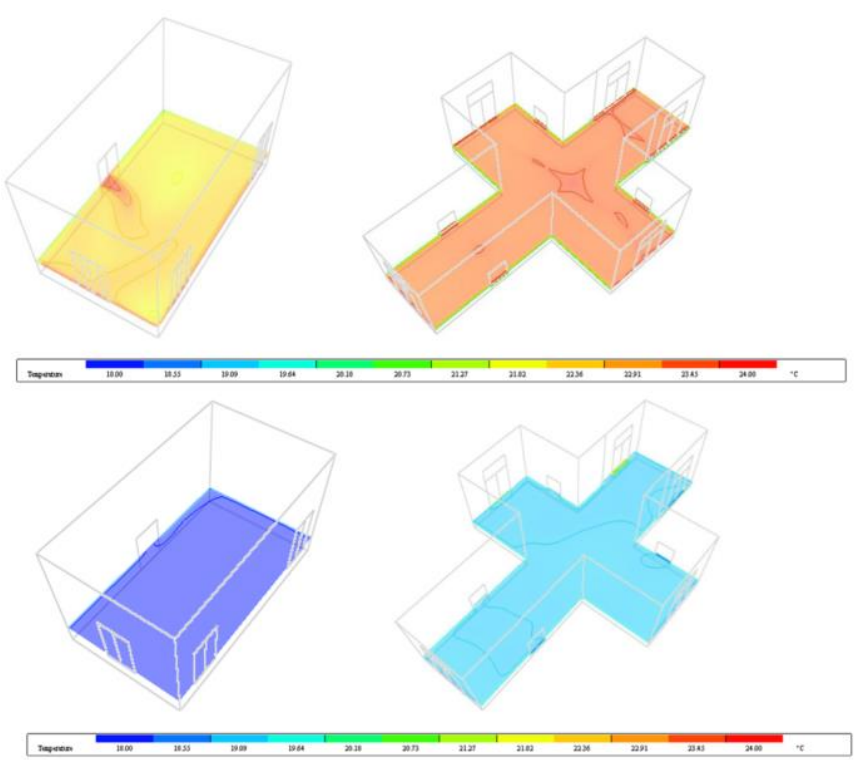

Figure 10. Indoor air temperature distribution in building simulation, in Summer ( $2^{\text {nd }}$ July 2016) Tribunale D'Amore (topleft picture) and Croce Centrale (top-right picture) and in Winter (29th December 2016) Tribunale D'Amore (bottom-left picture) and Croce Centrale (bottom-right picture).

Therefore, setting the software IES.VE with the input of "HVAC-ON" (set-point of $24^{\circ} \mathrm{C}$ and $18^{\circ} \mathrm{C}$ ) the outcome of the temperature will respect the suggested range.

This condition would mean an improvement of the visitors' comfort too. Indeed, Figure 11 shows the PPD (Predicted Percentage of Dissatisfied) simulation in both scenarios: HVAC-ON (simulated condition) and HVAC-OFF (current condition, perceived by visitors). To evaluate the PPD we assumed a level of sedentary activity in Summer $\left(69.8 \mathrm{~W} / \mathrm{m}^{2}\right.$ which is the equivalent of about $1.1 \mathrm{met}$ ) and the use of summer clothes, from which a thermal clothing resistance of 0.2 clo is obtained. For the Winter period we assumed a level of sedentary activity too $\left(69.8 \mathrm{~W} / \mathrm{m}^{2}\right)$, but with winter clothes: 1.2 clo of thermal resistance.

It is noted that all results over the comfort and discomfort PPD evaluation of visitors are related to a standard user, who stays in the room as provided for by ISO 7730. Moreover, when we talk about tourists or visitors' comfort in heritage buildings, the short duration of the visit and the seasonal clothing should be borne in mind. Anyway, the conservation of the artefacts is the priority. 


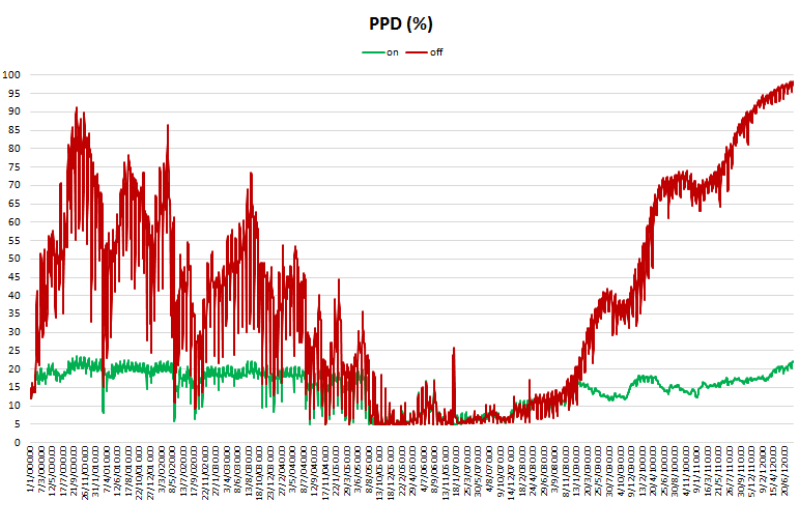

Figure 11: PPD Simulation, HVAC on-off, room Croce Centrale, IES.VE simulation.

\section{CONCLUSIONS}

Indoor microclimate is a fundamental aspect for Cultural Heritage, even more so if the artefacts are susceptible to thermal oscillations. The deformations caused by specific RH and T levels, which accelerate the deterioration process of artefacts, tend to be reversible in modern materials, such as plastic; but they are irreversible in ancient materials. A research methodology which allows to express a unique index, like the HMR index, and the analysis of each variable recorded and simulated, allows to adopt conservation and management strategies suitable for each specific context, bypassing, as has been said, all the difficulties connected to the use of many different standards over the same subject.

The possibility to formulate a hypothetical scenario, which brought forward an important microclimate change inside Villa Barbaro, confirms one of the strengths of the proposed methodology: it allows to consider the results of structural or management changes in advance, such as the opening and closing of doors and windows; access of visitors; changes in the HVAC systems, etc. with no actual negative effect on the historic building.

Moreover, if an artefact has been in certain microclimatic conditions for a long time, like Villa Barbaro (for ages), the internal tensions which have been caused could negatively respond to the unexpected climate changes: the conditions of the ancient artefact could risk being compromised. As a matter of fact, the decision to intervene with the activation of the HVAC system can't be taken easily: in terms of usefulness, this kind of intervention is easy to support if we are working to increase human comfort, but it is harder to evaluate the effect on the works of art. That confirms the releance of the history of a building and its contents, consequently of the HIM study. It is therefore of fundamental importance to study the environment where an artefact is, with regard to the architectural structure, as well as the local climatology aspects, including the study of the daily cycles and seasonality.

The visitors' comfort can be considered irrelevant for this case study because the duration of the visits is very short: around one hour; this point could be a subject for discussion in other researches, also in the field of Environmental Psychology and Heritage Tourism.

In conclusion, from our point of view, considering also the current researches, the Villa Barbaro case study allowed us to understand the necessity of changing perspective: moving from the definition of the singular artefact tolerance range, to the study of the indoor microclimate's aggressiveness.

\section{ACKNOWLEDGEMENTS}

The authors acknowledge Donna Diamante for her kindness and availability shown during our research.

\section{REFERENCES}

G. Thomson, The museum environment, 2nd ed., London, 1986. D. Camuffo, Microclimate for Cultural Heritage, Amsterdam, 1998.

A. Bernardi, Microclimate Inside Cultural Heritage Buildings, Padua, 2008

G. De Guichen, G. Medio siglo de Conservación Preventiva. Entrevista a Gaël de Guichen, Medio siglo de Conservación Preventiva. Entrevista a Gaël de Guichen, Ge-Conservación. 35-44 (2009).

F. Kristian, M. Pretelli, Historic Indoor Microclimate (HIM): a new challange in heritage building, in: n.d.

F.M.P. Kristian, Historic Indoor Microclimate of the Heritage Buildings: A Guideline for Professionals who care for Heritage Buildings, n.d. doi:10.1007/978-3-319-60343-8.

G. Litti, A. Audenaert, K. Fabbri, Indoor Microclimate Quality (IMQ) certification in heritage and museum buildings: The case study of Vleeshuis museum in Antwerp, Build. Environ. 124 (2017) 478-491. doi:10.1016/j.buildenv.2017.08.013.

S.P. Corgnati, V. Fabi, M. Filippi, A methodology for microclimatic quality evaluation in museums: Application to a temporary exhibit, Build. Environ. 44 (2009) 1253-1260. doi:10.1016/j.buildenv.2008.09.012.

S.N. Kamaruzzaman, C.O. Egbu, E.M.A. Zawawi, A.S. Ali, A.I. Che-Ani, The effect of indoor environmental quality on occupants' perception of performance: A case study of refurbished historic buildings in Malaysia, Energy Build. 43 (2011) 407-413. doi:10.1016/j.enbuild.2010.10.003.

J. Ferdyn-Grygierek, Monitoring of indoor air parameters in large museum exhibition halls with and without air-conditioning systems, Build. Environ. 107 (2016) 113-126. doi:10.1016/j.buildenv.2016.07.024.

J. Ferdyn-Grygierek, Indoor environment quality in the museum building and its effect on heating and cooling demand, Energy Build. 85 (2014) 32-44. doi:10.1016/j.enbuild.2014.09.014.

EN 15251, Indoor environmental input parameters for design and assessment of energy performance of buildings addressing indoor air quality, thermal environment, lighting and acoustic, UNI. (2008).

K. Fabbri, M. Pretelli, Heritage buildings and historic microclimate without HVAC technology: Malatestiana Library in Cesena, Italy, UNESCO Memory of the World, Energy Build. 76 (2014) 15-31. doi:10.1016/j.enbuild.2014.02.051.

M. Andretta, F. Coppola, L. Seccia, Investigation on the interaction between the outdoor environment and the indoor microclimate of a historical library, J. Cult. Herit. 17 (2016) 7586. doi:10.1016/j.culher.2015.07.002. 
S.P. Corgnati, M. Filippi, Assessment of thermo-hygrometric quality in museums: Method and in-field application to the " Duccio di Buoninsegna" exhibition at Santa Maria della Scala (Siena, Italy), J. Cult. Herit. 11 (2010) 345-349. doi:10.1016/j.culher.2009.05.003.

M. La Gennusa, G. Rizzo, G. Scaccianoce, F. Nicoletti, Control of indoor environments in heritage buildings: Experimental measurements in an old Italian museum and proposal of a methodology, J. Cult. Herit. 6 (2005) 147-155. doi:10.1016/j.culher.2005.03.001.

M. Ryhl-Svendsen, The Indoor Climate in Historic Buidings without Mechanical Ventilation Systems, Microclim. Indoor Monit. Cult. Herit. Preserv. (2005).

A. Martínez-Molina, I. Tort-Ausina, S. Cho, J.L. Vivancos, Energy efficiency and thermal comfort in historic buildings: A review, Renew. Sustain. Energy Rev. 61 (2016) 70-85. doi:10.1016/j.rser.2016.03.018.

C. Bonacina, P. Baggio, F. Cappelletti, P. Romagnoni, A.G. Stevan, The Scrovegni Chapel: The results of over 20 years of indoor climate monitoring, Energy Build. 95 (2015) 144-152. doi:10.1016/j.enbuild.2014.12.018.

F. Sciurpi, C. Carletti, G. Cellai, L. Pierangioli, Environmental monitoring and microclimatic control strategies in "la Specola" museum of Florence, Energy Build. 95 (2015) 190-201. doi:10.1016/j.enbuild.2014.10.061.

V. D'Agostino, F.R. D'Ambrosio Alfano, B.I. Palella, G. Riccio, The museum environment: A protocol for evaluation of microclimatic conditions, Energy Build. 95 (2015) 124-129. doi:10.1016/j.enbuild.2014.11.009.

R.P. Kramer, H.L. Schellen, A.W.M. van Schijndel, Impact of ASHRAE's museum climate classes on energy consumption and indoor climate fluctuations: Full-scale measurements in museum Hermitage Amsterdam, Energy Build. 130 (2016) 286294. doi:10.1016/j.enbuild.2016.08.016.

G. Pavlogeorgatos, Environmental parameters in museums, Build. Environ. 38 (2003) 1457-1462. doi:10.1016/S03601323(03)00113-6.

S.M.H.L. Ankersmit B., Managing Indoor Climate Risks in Museums, Original D, Springer, International Publishing, Amsterdam, 2017, Amsterdam, 2017.

ANSI/ASHRAE, Energy Guideline for Historical Buildings, (2015) 66.

MIBACT, Ref.B) MIBACT, Ministerial Decree, Atto di indirizzo sui criteri tecnico-scientifici e sugli standard di funzionamento e sviluppo dei musei, 10th May 2001, (2001). ISO 11799, Information and documentation - Document storage requiremnts for archive an lirary materials, Standard. (2003).

UNI EN 15757:2013, Conservazione dei Beni Culturali Specifiche concernenti la temperatura e l'umidità relativa per limitare i danni meccanici causati dal clima ai materiali organici igroscopici, (2013).

H.E. Silva, F.M.A. Henriques, T.A.S. Henriques, G. Coelho, A sequential process to assess and optimize the indoor climate in museums, Build. Environ. 104 (2016) 21-34. doi:10.1016/j.buildenv.2016.04.023.

E. Lucchi, Multidisciplinary risk-based analysis for supporting the decision making process on conservation, energy efficiency, and human comfort in museum buildings, J. Cult. Herit. 22 (2016) 1079-1089. doi:10.1016/j.culher.2016.06.001.

E. Lucchi, Review of preventive conservation in museum buidings, (2017) 1-14.

A.W. Brokerhof, B. Ankersmit, F. Ligterink, Risk Management for Collections, 2017.

G. Chiari, D. Camuffo, E. Conrad, M. Henry, R. Kerschner, K. Roman, S. Maekawa, S. Michalski, T. Oreszczyn, T. Padfield, H.L. Schellen, S. Staniforth, F. Toledo, Experts' Roundtable on Sustainable Climate Management Strategies Introduction, in: Ed. Transcr. Expert. Roundtable Sustain. Clim. Manag. Strateg. Held April 2007, Tenerife, Spain, 2007: pp. 1-98.

D. Camuffo, P. Brimblecombe, R. Van Grieken, H.J. Busse, G. Sturaro, A. Valentino, A. Bernardi, N. Blades, D. Shooter, L. De Bock, K. Gysels, M. Wieser, O. Kim, Indoor air quality at the Correr Museum, Venice, Italy, Sci. Total Environ. 236 (1999) 135-152. doi:10.1016/S0048-9697(99)00262-4.

S. Costanzo, A. Cusumano, C. Giaconia, G. Giaconia, Preservation of the artistic heritage within the seat of the Chancellorship of the University of Palermo. A proposal on a methodology regarding an environmental investigation according to Italian Standards, Build. Environ. 41 (2006) 18471859. doi:10.1016/j.buildenv.2005.06.010.

UNI EN 15758, Conservation of Cultural Property Procedures and instruments for measuring temperatures of the air and the surfaces of objects, (2012).

UNI 10829, Works of art of historical importance. Ambient conditions for the conservation. Measurement and analysis, (2011).

UNI 11131, Cultural heritage Field measurement of the air humidity, (2005).

U. 11120, Cultural heritage. Field measurement of the air temperature and the surface temperature of objects, (2001).

EN 15759-1:2011, Conservation of cultural property - Indoor climate - Part 1: Guidelines for heating churches, chapels and other places of worship Contents, (2011) 1-24.

IES.VE, https://www.iesve.com/ (Last visit 4/1/2018), (n.d.).

ISO, ISO 7730:2005, INTERNATIONAL STANDARD ISO environment - Analytical determination, Iso. 2005 (2005). ANSI/ASHRAE, ASHRAE Guideline 14-2002 Measurement of Energy and Demand Savings, Ashrae. 8400 (2002) 170.

M. Royapoor, T. Roskilly, Building model calibration using energy and environmental data, 94 (2015) 109-120.

F. Roberti, U.F. Oberegger, A. Gasparella, Calibrating historic building energy models to hourly indoor air and surface temperatures: Methodology and case study, Energy Build. 108 (2015) 236-243. doi:10.1016/j.enbuild.2015.09.010. 